\title{
The biology and genome of Heterorhabditis bacteriophora*
}

\author{
Todd Ciche ${ }^{\S}$, Department of Microbiology and Molecular Genetics, \\ Michigan State University, East Lansing, MI 48824 USA
}

\section{Table of Contents}

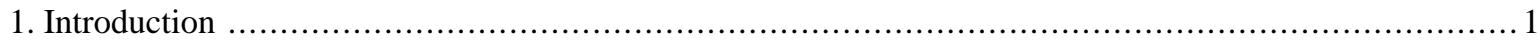

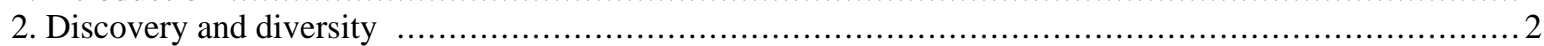

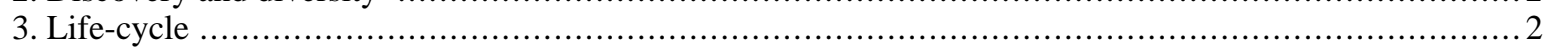

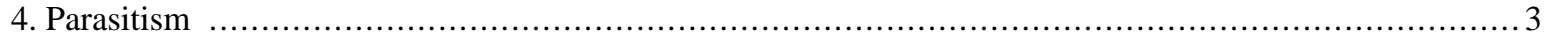

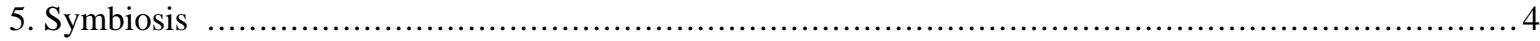

6. Other biology of interest for Heterorhabditis .......................................................... 5

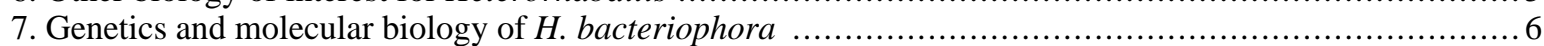

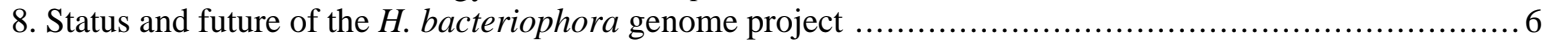

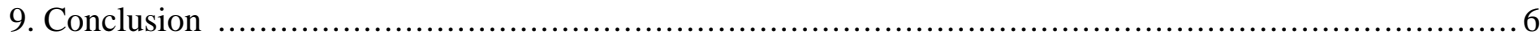

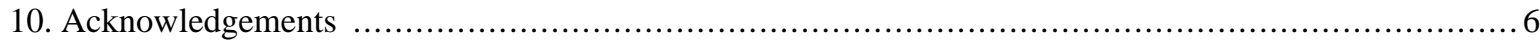

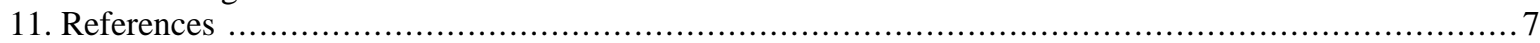

\begin{abstract}
Heterorhabditis bacteriophora is an entomopathogenic nematode (EPN) mutually associated with the enteric bacterium, Photorhabdus luminescens, used globally for the biological control of insects. Much of the previous research concerning $\boldsymbol{H}$. bacteriophora has dealt with applied aspects related to biological control. However, $\boldsymbol{H}$. bacteriophora is an excellent model to investigate fundamental processes such as parasitism and mutualism in addition to its comparative value to Caenorhabditis elegans. In June 2005, H. bacteriophora was targeted by NHGRI for a high quality genome sequence. This chapter summarizes the biology of $H$. bacteriophora in common and distinct from $C$. elegans, as well as the status of the genome project.
\end{abstract}

\section{Introduction}

Much of the interest in Heterorhabditis bacteriophora nematodes relates to its intimate interactions with other organisms. H. bacteriophora is an insect parasite used for the biological control of insects and an obligate host for symbiotic Photorhabdus luminescens bacteria (Forst et al., 1997; see Figure 1). Transmission of symbiotic bacteria by the infective juvenile (IJ) stage nematodes is essential for the nematode to successfully parasitize insects and to

\footnotetext{
*Edited by Jonathan Hodgkin and Philip Anderson. Last revised November 22, 2006. Published February 20, 2007. This chapter should be cited as: Ciche, T. The biology and genome of Heterorhabditis bacteriophora (February 20, 2007), WormBook, ed. The C. elegans Research Community, WormBook, doi/10.1895/wormbook.1.135.1, http://www.wormbook.org.

Copyright: (C) 2007 Todd Ciche. This is an open-access article distributed under the terms of the Creative Commons Attribution License, which permits unrestricted use, distribution, and reproduction in any medium, provided the original author and source are credited.

${ }^{\S}$ To whom correspondence should be addressed. Tel: 405 271-7681. E-mail: ciche@ msu.edu
} 
reproduce (Han and Ehlers, 2000). Hence, this association can also be described as an obligate (for nematode and symbiont) vector-borne disease of insects. H. bacteriophora can also be described as a bacteriovore dependent on symbiotic P. luminescens for growth and reproduction. However, classifying $H$. bacteriophora as a bacteriovore ignores the parasitic adaptations such as host finding, buccal tooth used to penetrate the insect exoskeleton (Bedding and Molyneux, 1982), regurgitation of intestinal symbionts after sensing host cue(s) (Ciche and Ensign, 2003), and its symbiotic association with $P$. luminescens bacteria. H. bacteriophora is a rhabditid nematode in the eurhabditid clade along with $C$. elegans and strongylid parasites (see The phylogenetic relationships of Caenorhabditis and other rhabditids). Thus, unique characteristics such as parasitism, biological control and symbiosis can be studied utilizing the knowledge base and resources of $C$. elegans. In June 2005, NHGRI targeted H. bacteriophora for a high quality draft genome sequence. The knowledge obtained from the genome sequence should rapidly establish this nematode as an animal model for parasitism, symbiosis, vector-born disease and its application for the biological control of insects.

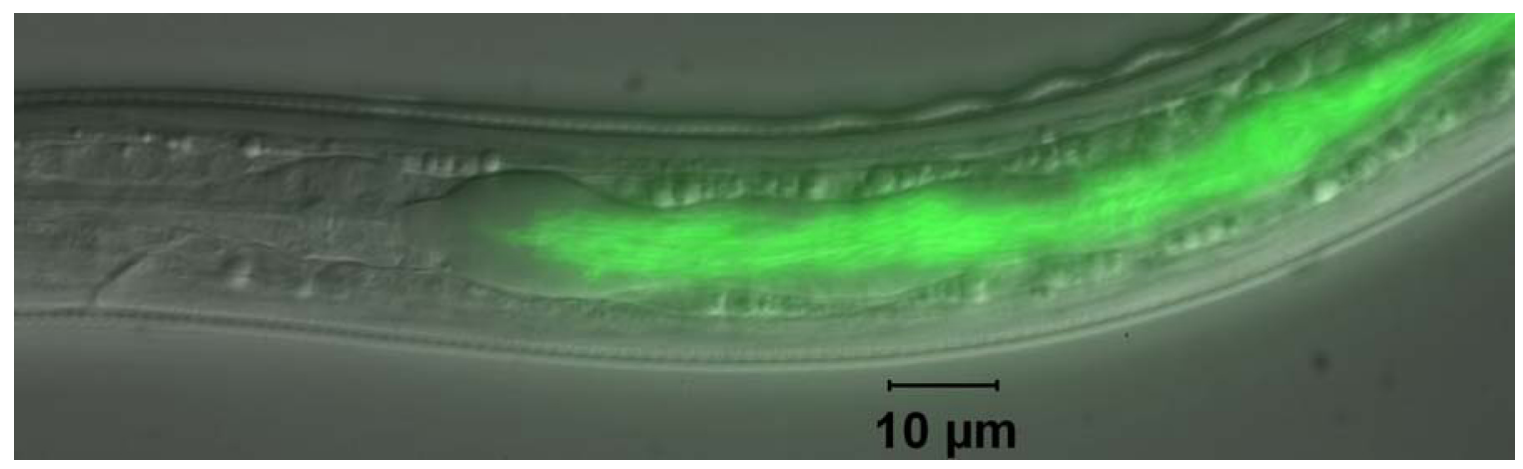

Figure 1. GFP-labeled Photorhabdus luminescens in the intestine of the developmentally arrested infective juvenile (IJ) stage of Heterorhabditis bacteriophora nematode. Transmission of symbiotic bacteria in the IJ is necessary for the nematode and bacteria to infect insects and for nematode reproduction.

\section{Discovery and diversity}

The insect parasitic (entomopathogenic) nematode, Heterorhabditis bacteriophora, was first described in 1975 as a new genus, species, and family (Heterorhabditidae) of Rhabditida (Poinar, 1975). The infective juvenile (IJ) stage, which is similar to the dauer juvenile stage of $C$. elegans, was found to transmit a specific Gram-negative bacterium in the anterior intestine to the hemocoel of insect hosts (Poinar et al., 1977). This bacterium was first described as Xenorhabdus luminescens, along with Xenorhabdus nematophila which is associated with the distantly related insect parasitic nematode, Steinernema carpocapsae (Thomas and Poinar, 1979). This bacterium is now called Photorhabdus luminescens subspecies luminescens (Fischer-Le Saux et al., 1999). Several Heterorhabditis species have been described (Adams et al., 2006; Hominick et al., 1997) and studied for their biological control potential. In 2003, the complete genome sequence of a H. bacteriophora symbiont, Photorhabdus luminescens subsp. laumondii strain TT01 isolated from Trinidad and Tobago, was published (Duchaud et al., 2003). Because of the available symbiont genome sequence, the H. bacteriophora genome consortium chose $H$. bacteriophora for the genome sequence and to use as a model for further studies.

\section{Life-cycle}

The non-feeding and developmentally arrested IJ is the only stage of $H$. bacteriophora found outside of insect hosts in nature. IJs exist, often in soil, containing a monoculture of symbiotic bacteria in their intestinal lumen while in search for an insect host (see Figure 1). The IJs sense an insect host, enter the hemocoel and regurgitate symbiotic bacteria into the insect hemocoel (see Figure 1 and Movie 1; Ciche and Ensign, 2003). The bacteria rapidly kill the insect, usually in less than 24 hours. The bacterium is the main cause of insect mortality since the bacterium alone has an $\mathrm{LD}_{50}<10$ cells when injected the insect hemocoel (Milstead, 1979) and axenic IJs do not cause insect mortality nor proliferate without symbiotic bacteria present (Han and Ehlers, 2000). Symbiotic bacteria provide a protected niche for themselves and host nematodes by producing antibiotics (Akhurst, 1982; Hu and Webster, 2000; Paul et al., 1981; Richardson et al., 1988), nematicide (Hu et al., 1999) and even compounds which deter scavenging ants (Zhou et al., 2002). The nematodes grow and reproduce for 2-3 generations on symbiotic bacteria before generating IJs en masse, most transmitting symbiotic bacteria. 


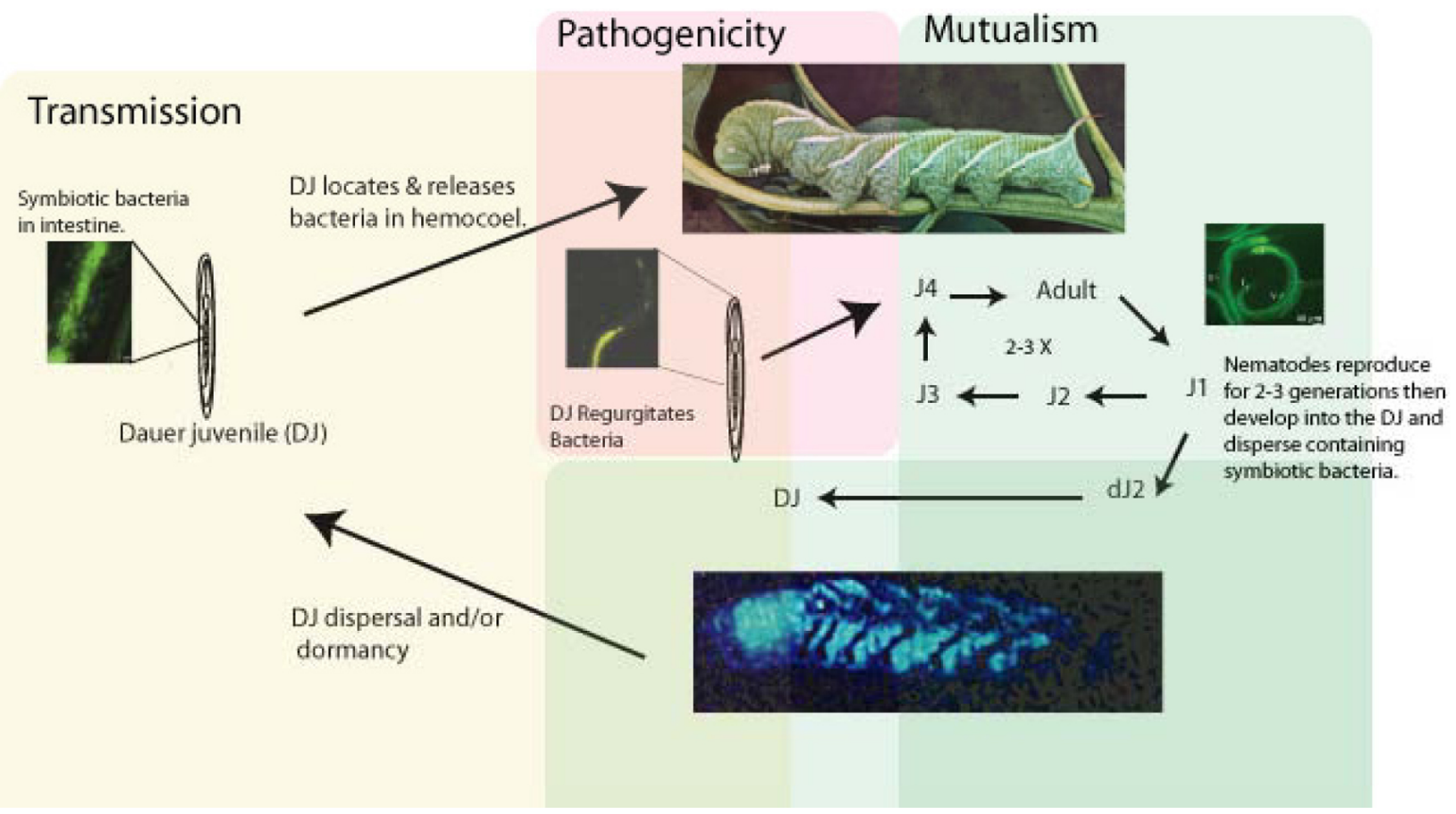

Figure 2. Life-cycle of $\boldsymbol{H}$. bacteriophora. The non-feeding IJ stage, a dauer juvenile (DJ) stage that infects insects, exists in soil containing a monoculture of symbiotic bacteria in its intestinal lumen, sometimes for many months until an insect host is found. The DJs locate an insect host and enter the hemocoel, where they regurgitate symbiotic bacteria. The bacteria rapidly kill the insect and produce metabolites to inhibit microbial, nematode and arthropod competitors. After 2-3 generations, DJs are again formed and emerge en masse transmitting symbiotic bacteria. Adapted from Ciche et al. (2006), with permission from Elsevier.

\section{Parasitism}

Entomopathogenic IJs employ different foraging behaviors to infect insect hosts, cruiser and ambusher strategies (Lewis et al., 1995). H. bacteriophora is a cruiser forager meaning that it actively seeks out or hunts its prey. In addition to sensing $\mathrm{CO}_{2}$ and volatile cues (O'Halloran and Burnell, 2002) released by the host, IJs are attracted to (E)-beta-caryophyllene, a terpene released by plant roots upon herbivore damage (Rasmann et al., 2005). Thus, IJs have evolved chemosensory mechanisms not only to detect insect hosts, but also locations where insect hosts are likely to be present. When in contact with an insect host, the IJs exsheath the previously retained $\mathbf{J} 2$ cuticle and enter the hemocoel through the insect mouth, anus or spiracles or by penetrating the exoskeleton using a buccal 'tooth'-like structure (Bedding and Molyneux, 1982). Once inside the insect hemocoel, the IJs must contend with the sophisticated innate immune defenses of the insect. Insects defend against large organisms by encapsulation and activation of phenol oxidase cascade, the latter is observed by a black appearance due to melanin production (Gillespie et al., 1997). Insects also have Toll-like receptors that detect pathogen associated molecular patterns (PAMPs) which in turn activate antimicrobial peptides (Lemaitre et al., 1997). H. bacteriophora and/or associated bacteria either avoid or suppress these immune defenses since IJs are not encapsulated (Peters et al., 1997) and infected insects do not turn black.

After IJ entry into insect hemocoel, it releases the symbiotic bacteria. Using GFP-labeled symbionts located in the IJ intestines, it was observed that the IJs regurgitate symbiotic bacteria (Ciche and Ensign, 2003; see Movie 1). After a 30 minute lag, IJs regurgitate symbiotic bacteria in a pulsatile and staggered manner at an average rate of 1 cell released every 2 minutes. The regurgitation inducing cues were present in all arthropod hemolymph and insect cell culture supernatants tested, but not in vertebrate blood or P. luminescens culture supernatants. The cue(s) was also shown to be heat and protease resistant and less than >5000 Da MW. The nematodes provide the mechanical force for regurgitation because IJs treated with levamisole and ivermectin fail to expel the bacteria and the bacteria are not motile initially after release. 


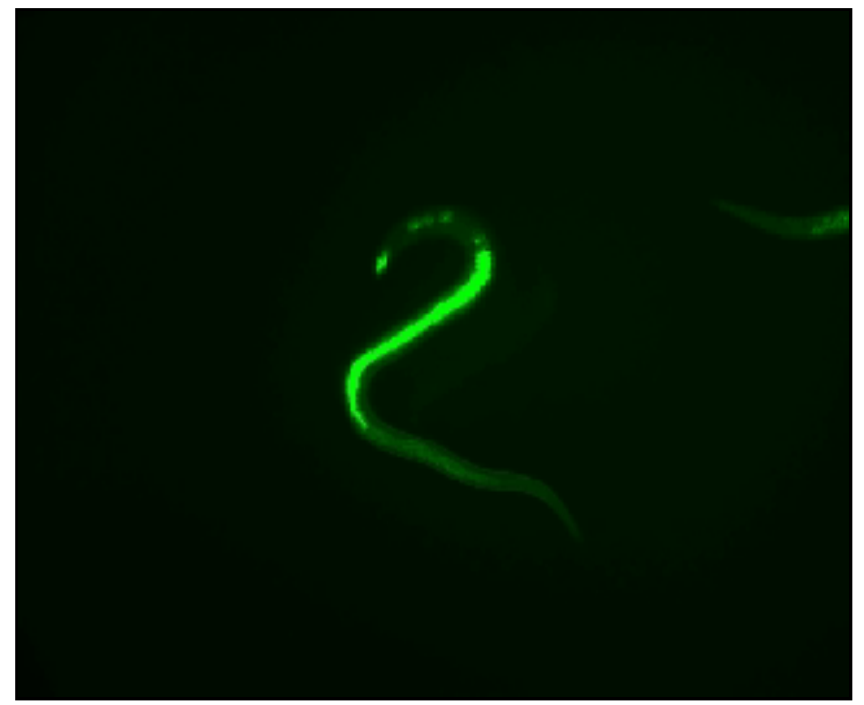

Movie 1. Regurgitation of GFP-labeled $P$. luminescens by IJs. Time-lapse approximately 2x speed showing regurgitation of GFP-labeled $P$. luminescens by IJs immersed in hemolymph of $3^{\text {rd }}$ instar Manduca sexta (tobacco hornworm) larvae. After a 30 minute lag, the bacteria are released in a pulsatile and staggered manner, at an average rate of 1 release bacter/ 2 minutes for more than 5 hours.

Like many nematode parasites, $H$. bacteriophora infects with a stage analogous to the dauer stage of $C$. elegans. Exiting the developmentally arrested IJ during infection is analogous to dauer recovery in C. elegans, as exemplified by common muscarinic signaling involved in Ancyclostoma caninum and C. elegans dauer recovery (Tissenbaum et al., 2000). H. bacteriophora provides an excellent model to study parasitism because insect larvae can be used as hosts. Moreover, induction of parasitism can be assayed by monitoring the release of $P$. luminescens by IJs incubated in insect cell supernatants (Ciche and Ensign, 2003). Although P. luminescens is the main cause for insect pathogenicity, $H$. bacteriophora IJs likely contribute to insect virulence, for example through immune suppression.

\section{Symbiosis}

The symbiosis between $H$. bacteriophora and $P$. luminescens is potentially one of the most tractable symbiosis models. $H$. bacteriophora shares many attributes with $C$. elegans such as, short generation time, high fecundity, hermaphroditic and gonochoristic modes of reproduction, small size, transparency and small genome size. $P$. luminescens is an enteric $\gamma$-Proteobacterium that shares many virulence factors with medically relevant pathogens and the complete genome sequence is known (Duchaud et al., 2003). Thus genomes will be available for both partners of this symbiosis and genetics are established in P. luminescens and being developed in H. bacteriophora. The most important characteristic of this symbiosis, in my opinion, is that it is obligate in nature. Since $H$. bacteriophora and $P$. luminescens require each other to reproduce in nature, strong selective pressure is likely applied to ensure proper establishment and maintenance of the symbiosis. Two important symbiotic processes are the selective transmission of $P$. luminescens by IJs and the requirement of $P$. luminescens for nematode growth and reproduction (Ciche et al., 2006). However, symbiotic bacteria are likely to influence other developmental and physiological processes in H. bacteriophora, e.g., by the production of food signals (Strauch and Ehlers, 1998).

$H$. bacteriophora must transmit $P$. luminescens to infect and proliferate inside insects. Axenic nematodes do not cause insect mortality and do not proliferate inside the insect cadavers (limited reproduction occurs generating L1s which fail to develop further; Han and Ehlers, 2000). Thus, H. bacteriophora IJs selectively transmit symbiotic P. luminescens or related strains (Gerritsen and Smits, 1993). Furthermore, when H. bacteriophora are grown on lawns of the $P$. temperata symbiont of $H$. megidis, no $P$. temperata are transmitted (Han and Ehlers, 2000). However, transmission is not strictly species specific since a $P$. temperata strain C1 (ATCC 29304) symbiont of $H$. bacteriophora nematodes is transmitted by $H$. bacteriophora TT01 (Ciche, unpublished).

The processes and molecular mechanisms of symbiont transmission in $H$. bacteriophora is not well understood and is a major focus of research in my laboratory (I will update this chapter accordingly as new findings are published). The ngrA gene is required for $P$. temperata to support $H$. bacteriophora growth and development (discussed below) and is unable to compete with wild-type bacteria during IJ colonization, but colonizes normally 
when grown with $P$. temperata Meg/1, a strain not transmitted by H. bacteriophora nematodes (Ciche et al., 2001). The $n g r A$ gene encodes a putative $4^{\prime}$-phosphopantetheinyl transferase (PPTase) that is likely required for acyl- and peptidyl- carrier proteins that function for the biosynthesis of fatty acids, polyketides and non-ribosomally synthesized peptides (Quadri et al., 1998). Thus, it is the absence of holo-carrier protein(s) and corresponding secondary metabolites that is likely involved in transmission. In another study, a mutant in the pbgPE operon, involved in the synthesis of O-antigen component of lipopolysaccharide, was transmitted $1 \%$ compared to wild type and was not transmitted when cocultured with wild-type bacteria (Bennett and Clarke, 2005). A pbgPE mutant is also sensitive to mildly acidic conditions and to the cationic antibiotic polymyxin, suggesting that these stresses might be employed by the nematode to selectively transmit $P$. luminescens bacteria.

In contrast to more general bacteriovores like $C$. elegans, $H$. bacteriophora requires $P$. luminescens or $P$. temperata as a substrate for growth and development (Akhurst et al., 1996) and is very sensitive to contaminating microbes compared to C. elegans. In addition, the primary form is required for nematode growth and development. The primary form is isolated from IJs and infected insects and switches to the secondary phase variant upon prolonged subculturing (Akhurst, 1980). The primary form can be distinguished from the secondary variant by differential dye uptake, bioluminescence, colony morphology (mucoid, pigmented and opaque primary form colonies), antibiotic, and exoenzyme production, and production of two intracellular crystalline inclusion proteins, CipA and CipB (Akhurst, 1980; Bintrim and Ensign, 1998).

The Cips can account for as much as $40 \%$ of total protein and are unusually high in essential amino acid content (Bintrim and Ensign, 1998). Both $\operatorname{cipA}$ and $\operatorname{cipB}$ were cloned and disrupted by allelic exchange and neither mutant supported nematode growth and development (Bintrim and Ensign, 1998). The mutant cip strains were phenotypically intermediate between the primary form and the secondary phase. Thus, the inability of the cip mutants to support nematode growth and reproduction might be related to other secondary phase variant characteristics than Cip production.

To determine other genes required for the bacterium to support nematode growth and reproduction, transposon mutants were screened for their inability to support nematode growth and reproduction. Mutant NGR209 was completely defective in supporting nematode growth and reproduction while retaining most primary form characteristics (Ciche et al., 2001). The ngrA gene, encoding a putative 4'-phosphopantetheinyl transferase (PPTase), was found to contain a transposon insertion causal for the symbiotic defect of NGR209. As already discussed above, PPTases transfer 4'-phosphopantothenate to serine residues on acyl- or peptidyl carrier proteins involved the biosynthesis of a great variety of secondary metabolites. NGR209 was defective in producing antibiotic and siderophore (microbial compounds that chelate iron) activities. Thus, these metabolites, or another metabolite, likely function to signal directly or indirectly for nematode growth and reproduction (Ciche et al., 2001). The production of siderophores was shown not to be necessary for nematode growth and reproduction since a mutant in a peptidyl carrier protein required for the synthesis of photobactin siderophore supported nematode growth and reproduction to the extent of wild type (Ciche et al., 2003). However when a siderophore transport related gene, $\operatorname{expD}$, was disrupted, the mutant bacteria no longer supported nematode growth and reproduction. This defect was complemented by the addition of iron, suggesting a role for iron metabolism for the bacteria to support nematode growth and reproduction (Watson et al., 2005).

In addition to the production or lack thereof of nematode growth and reproduction activity, some Photorhabdus spp. antagonize non-symbiotic nematodes. This seems to be the case with the P. luminescens subsp. luminescens associated with $H$. indica nematodes (Han and Ehlers, 1999).

Although most Photorhabdus are toxic to C. elegans and other nematodes, some are toxic to Heterorhabditis nematodes. Much remains to be learned regarding nematode growth and reproduction activity of symbiotic Photorhabdus as well as the antagonism towards non-symbiotic nematodes.

\section{Other biology of interest for Heterorhabditis}

Many biological processes well-known in C. elegans will be of great interest to study in H. bacteriophora in relation to symbiosis and parasitism. Examples of these are dauer recovery and formation in relation to parasitism and symbiont transmission, and innate immunity in relation to symbiont transmission. Processes such as resistance to stress and desiccation and dauer longevity are also of interest since they may lead to increased efficacy or increased shelf-life of EPNs used for biological control of insects. However, the heterogonic mode of reproduction of $\mathrm{H}$. bacteriophora is rare in rhabditids (see The phylogenetic relationships of Caenorhabditis and other rhabditids). H. bacteriophora IJs develop into hermaphrodites and these in turn can lay eggs that develop into 
hermaphrodites, females or males. When egg laying ceases, worms develop inside the maternal body cavity by a process called endotokia matricida (Johnigk and Ehlers, 1999). Interestingly, worms that develop by endotokia matricida are predominantly hermaphroditic IJs (Dix et al., 1992). Thus, it appears that individual worms can change the sex of their offspring. Nothing is known at the molecular level concerning this heterogonic mode of reproduction and the genome sequence should provide sex determination related genes shared and absent in $H$. bacteriophora as compared to C. elegans.

\section{Genetics and molecular biology of $\boldsymbol{H}$. bacteriophora}

H. bacteriophora can be cultivated on agar plates containing the primary form of $P$. luminescens or $P$. temperata (Lunau et al., 1993). Successful mutagenesis of $H$. bacteriophora using EMS similar to the procedure used for C. elegans has been published (Koltai et al., 1994). Transformation of H. bacteriophora by microinjection has also been published (Hashmi et al., 1995; Hashmi et al., 1997). Furthermore, RNAi gene silencing by soaking is successful in H. bacteriophora (Ciche and Sternberg unpublished). A protocol for the successful cryopreservation of Heterorhabditis species has been developed (Nugent et al., 1996). Despite these encouraging results, development of genetics and molecular biology in Heterorhabditis is still in the early stages. Few mutants have been published in Heterorhabditis and there is no genetic map. Transformation by microinjection has not been repeated since the initial reports. Along with the high quality draft genome sequence, generation of a physical map is planned for the H. bacteriophora genome project. The genome and a physical map, along with the development of RNAi and transformation, should facilitate the development and use of genetic and molecular tools in H. bacteriophora.

\section{Status and future of the $\boldsymbol{H}$. bacteriophora genome project}

In June 2005, NHGRI announced that it was targeting H. bacteriophora for a high quality (i.e., 6X coverage) draft genome sequence. This was partially due to the efforts and white paper produced by the H. bacteriophora genome consortium initiated at the EPN and associated bacteria meetings in Wooster, Ohio and Eilat, Israel in 2003 (Ciche et al., 2006). Heterorhabditis was chosen over other EPNs because of its relatedness to C. elegans, and $H$. bacteriophora strain TTO1 was chosen because the genome sequence of the mutually associated $P$. luminescens subsp. laumondii bacteria was completed (Duchaud et al., 2003). This strain was inbred for 13 generations by self-fertilizing individual IJs and distributed to the EPN community (Ciche and Sternberg unpublished). The genome size was determined to be $111.4+/-1.1 \mathrm{Mb}$ by Spencer Johnson using a flow cytometry technique (Bennett et al., 2003; The H. bacteriophora genome consortium, unpublished). Genomic DNA from the inbred line M31e purified from axenic IJs has been sent to Washington University Genome Sciences Center and is currently undergoing heterozygosity testing (see progress here: http://genome.wustl.edu/genome.cgi?GENOME=Heterorhabditis\%20 bacteriophora). Approximately 4600 sequence traces generated for heterozygosity testing have been deposited in the NCBI Trace Archive (linked to in the website listed above). Construction of a physical map and ESTs are also planned. Recently, an EST dataset (1246 ESTs) from H. bacteriophora strain GPS11 was analyzed (Sandhu et al., 2006). From 1072 useful ESTs analyzed, 417 had significant similarities to C. elegans and approximately $67 \%$ of the ESTs had no significant match in Genbank suggesting the possibility that a significant amount of novel genes expressed by IJ H. bacteriophora. It is evident from this data and initial genome data on the NCBI trace archive, that H. bacteriophora shares many signaling pathways with $C$. elegans. However, the large amount of genome data that will be available in the near future should greatly clarify comparisons to C. elegans and other nematodes. The high quality draft sequence, ESTs and a physical map will rapidly mature our knowledge of gene content, organization and expression and enable many studies, such as functional genomics to elucidate gene function in $H$. bacteriophora, for example, as related to parasitic or symbiotic biology.

\section{Conclusion}

H. bacteriophora is a nematode with applied value for the biological control of insects. H. bacteriophora also has value as a model to study processes not studied in C. elegans, including parasitism, symbiosis and heterogonic sex determination. Information from the genome project, along with comparisons to other nematode genomes, will provide us with a better understanding of what genes make a nematode a parasite and host for symbiotic bacteria.

\section{Acknowledgements}

I gratefully acknowledge the National Institutes of Health (NIH), National Human Genome Research Institute (NHGRI) for targeting $H$. bacteriophora for a high quality draft genome sequence and support from the Interagency National Science Foundation (NSF)/ United States Department of Agriculture (USDA)-Cooperative State Research, 
Education and Extension Service (CSREES) Microbial Genome Sequencing Project (07-165-0709). The energetic support and expertise from Paul Sternberg, consultations from members of Wormbase and John Spieth and Sandra Clifton at Washington University Genome Sciences Center were all critical for the successful funding of the genome project. I gratefully acknowledge Parwinder Grewal for being PI and providing leadership of the genome project, co-PIs Byron Adams, Randy Gaugler and Paul W. Sternberg and all members of the H. bacteriophora genome consortium. The Ciche lab is funded by the CSREES Microbial Genome Sequence Project and from funding though Michigan State University's Research for Excellence Funds-Center for Microbial Pathogenesis. I also thank two anonymous reviewers for valuable comments and suggestions.

\section{References}

Adams, B.J., Fodor, A., Koppenhofer, H.S., Stackebrandt, E., Patricia Stock, S., and Klein, M.G. (2006). Biodiversity and systematics of nematode-bacterium entomopathogens. Biol. Control 37, 32-49. Article

Akhurst, R.J. (1980). Morphological and Functional Dimorphism in Xenorhabdus Spp Bacteria Symbiotically Associated with the Insect Pathogenic Nematodes Neoaplectana and Heterorhabditis. J. Gen. Microbiol. 121, 303-309.

Akhurst, R.J. (1982). Antibiotic-Activity of Xenorhabdus Spp, Bacteria Symbiotically Associated with Insect Pathogenic Nematodes of the Families Heterorhabditidae and Steinernematidae. J. Gen. Microbiol. 128, 3061-3065. Abstract

Akhurst, R.J., Mourant, R.G., Baud, L., and Boemare, N.E. (1996). Phenotypic and DNA relatedness between nematode symbionts and clinical strains of the genus Photorhabdus (Enterobacteriaceae). Int. J. Syst. Bacteriol. 46, 1034-1041. Abstract

Bedding, R.A., and Molyneux, A.S. (1982). Penetration of insect cuticle by infective juveniles of Heterorhabditis spp heterorhabditidae nematoda. Nematologica 28, 354-359.

Bennett, H.P., and Clarke, D.J. (2005). The pbgPE operon in Photorhabdus luminescens is required for pathogenicity and symbiosis. J. Bacteriol. 187, 77-84. Abstract Article

Bennett, M.D., Leitch, I.J., Price, H.J., and Johnston, J.S. (2003). Comparisons with Caenorhabditis ( 100 Mb) and Drosophila ( $\sim 175 \mathrm{Mb})$ Using Flow Cytometry Show Genome Size in Arabidopsis to be $\sim 157 \mathrm{Mb}$ and thus $\sim 25 \%$ Larger than the Arabidopsis Genome Initiative Estimate of $\sim 125 \mathrm{Mb}$. Ann. Bot. 91, 547-557. Abstract Article

Bintrim, S.B., and Ensign, J.C. (1998). Insertional inactivation of genes encoding the crystalline inclusion proteins of Photorhabdus luminescens results in mutants with pleiotropic phenotypes. J. Bacteriol. 180, 1261-1269. Abstract

Ciche, T.A., Bintrim, S.B., Horswill, A.R., and Ensign, J.C. (2001). A phosphopantetheinyl transferase homolog is essential for Photorhabdus luminescens to support growth and reproduction of the entomopathogenic nematode Heterorhabditis bacteriophora. J. Bacteriol. 183, 3117-3126. Abstract Article

Ciche, T.A., Blackburn, M., Carney, J.R., and Ensign, J.C. (2003). Photobactin: a catechol siderophore produced by Photorhabdus luminescens, an entomopathogen mutually associated with Heterorhabditis bacteriophora NC1 nematodes. Appl. Environ. Microbiol. 69, 4706-4713. Abstract Article

Ciche, T.A., Darby, C., Ehlers, R.-U., Forst, S., and Goodrich-Blair, H. (2006). Dangerous liaisons: The symbiosis of entomopathogenic nematodes and bacteria. Biol. Control 38, 22-46. Article

Ciche, T.A., and Ensign, J.C. (2003). For the insect pathogen Photorhabdus luminescens, which end of a nematode is out? Appl. Environ. Microbiol. 69, 1890-1897. Abstract Article

Dix, I., Burnell, A.M., Griffin, C.T., Joyce, S.A., Nugent, M.J., and Downes, M.J. (1992). The identification of biological species in the genus Heterorhabditis nematoda heterorhabditidae by cross-breeding second-generation amphimictic adults. Parasitology 104, 509-518. 
Duchaud, E., Rusniok, C., Frangeul, L., Buchrieser, C., Givaudan, A., Taourit, S., Bocs, S., Boursaux-Eude, C., Chandler, M., Charles, J.F. , et al. (2003). The genome sequence of the entomopathogenic bacterium Photorhabdus luminescens. Nat. Biotechnol. 21, 1307-1313. Abstract Article

Fischer-Le Saux, M., Viallard, V., Brunel, B., Normand, P., and Boemare, N.E. (1999). Polyphasic classification of the genus Photorhabdus and proposal of new taxa: $P$. luminescens subsp. luminescens subsp. nov., $P$. luminescens subsp. akhurstii subsp.nov., P. luminescens subsp. laumondii subsp. nov., P. temperata sp. nov., P. temperata subsp. temperata subsp. nov. and P. asymbiotica sp. nov. Int. J. Syst. Bacteriol. 49, 1645-1656. Abstract

Forst, S., Dowds, B., Boemare, N., and Stackebrandt, E. (1997). Xenorhabdus and Photorhabdus spp.: bugs that kill bugs. Annu. Rev. Microbiol. 51, 47-72. Abstract Article

Gerritsen, L.J.M., and Smits, P.H. (1993). Variation in pathogenicity of recombinations of Heterorhabditis and Xenorhabdus luminescens strains. Fundam. Appl. Nematol. 16, 367-373.

Gillespie, J.P., Kanost, M.R., and Trenczek, T. (1997). Biological mediators of insect immunity. Annu. Rev. Entomol. 42, 611-643. Abstract Article

Han, R.C., and Ehlers, R.U. (1999). Trans-specific nematicidal activity of Photorhabdus luminescens. Nematology 1, 687-693. Article

Han, R.C., and Ehlers, R.U. (2000). Pathogenicity, development, and reproduction of Heterorhabditis bacteriophora and Steinernema carpocapsae under axenic in vivo conditions. J. Invertebr. Pathol. 75, 55-58. Abstract Article

Hashmi, S., Hashmi, G., and Gaugler, R. (1995). Genetic transformation of an entomopathogenic nematode by microinjection. J. Invertebr. Pathol. 66, 293-296. Abstract Article

Hashmi, S., Hatab, M.A.A., and Gaugler, R.R. (1997). GFP: Green fluorescent protein a versatile gene marker for entomopathogenic nematodes. Fundam. Appl. Nematol. 20, 323-327.

Hominick, W.M., Briscoe, B.R., del Pino, F.G., Heng, J., Hunt, D.J., Kozodoy, E., Mracek, Z., Nguyen, K.B., Reid, A.P., Spiridonov, S., et al. (1997). Biosystematics of entomopathogenic nematodes: current status, protocols and definitions. J. Helminthol. 71, 271-298. Abstract

Hu, K., and Webster, J.M. (2000). Antibiotic production in relation to bacterial growth and nematode development in Photorhabdus Heterorhabditis infected Galleria mellonella larvae. FEMS Microbiol. Lett. 189, $219-223$. Abstract

Hu, K.J., Li, J.X., and Webster, J.M. (1999). Nematicidal metabolites produced by Photorhabdus luminescens (Enterobacteriaceae), bacterial symbiont of entomopathogenic nematodes. Nematology 1, 457-469. Article

Johnigk, S.-A., and Ehlers, R.-U. (1999). Endotokia matricida in hermaphrodites of Heterorhabditis spp and the effect of the food supply. Nematology 1,717-726. Article

Koltai, H., Glazer, I., and Segal, D. (1994). Phenotypic and genetic characterization of two new mutants of Heterorhabditis bacteriophora. J. Nematol. 26, 32-39.

Lemaitre, B., Reichhart, J.M., and Hoffmann, J.A. (1997). Drosophila host defense: differential induction of antimicrobial peptide genes after infection by various classes of microorganisms. Proc. Natl. Acad. Sci. U.S.A. 94, 14614-14619. Abstract Article

Lewis, E.E., Selvan, S., Campbell, J.F., and Gaugler, R. (1995). Changes in foraging behaviour during the infective stage of entomopathogenic nematodes. Parasitology 110, 583-590.

Lunau, S., Stoessel, S., Schmidt-Peisker, A.J., and Ehlers, R.U. (1993). Establishment of monoxenic inocula for scaling up in vitro cultures of the entomopathogenic nematodes Steinernema spp and Heterorhabditis spp. Nematologica 39, 385-399. 
Milstead, J.E. (1979). Heterorhabditis bacteriophora as a vector for introducing its associated bacterium into the hemocoel of galleria-mellonella larvae. J. Invertebr. Pathol. 33, 324-327. Article

Nugent, M.J., O'Leary, S.A., and Burnell, A.M. (1996). Optimised procedures for the cryopreservation of different species of Heterorhabditis. Fundam. Appl. Nematol. 19, 1-6.

O'Halloran, D.M., and Burnell, A.M. (2002). Olfaction and odour discrimination in the insect parasitic nematode Heterorhabditis bacteriophora. Nematology 4, 206.

Paul, V.J., Frautschy, S., Fenical, W., and Nealson, K.H. (1981). Antibiotics in Microbial Ecology - Isolation and Structure Assignment of Several New Anti-Bacterial Compounds from the Insect-Symbiotic Bacteria Xenorhabdus Spp. J. Chem. Ecol. 7, 589-597. Article

Peters, A., Gouge, D.H., Ehlers, R.U., and Hague, N.G.M. (1997). Avoidance of encapsulation by Heterorhabditis spp infecting larvae of Tipula oleracea. J. Invertebr. Pathol. 70, 161-164. Abstract Article

Poinar, G.O.J. (1975). Description and biology of a new insect parasitic rhabditoid heterorhabditis-bacteriophora new-genus new-species rhabditida heterorhabditidae new family. Nematologica 21, 463-470.

Poinar, G.O.J., Thomas, G.M., and Hess, R. (1977). Characteristics of the specific bacterium associated with Heterorhabditis bacteriophora heterorhabditidae rhabditida. Nematologica 23, 97-102.

Quadri, L.E., Weinreb, P.H., Lei, M., Nakano, M.M., Zuber, P., and Walsh, C.T. (1998). Characterization of Sfp, a Bacillus subtilis phosphopantetheinyl transferase for peptidyl carrier protein domains in peptide synthetases. Biochemistry 37, 1585-1595. Abstract Article

Rasmann, S., Kollner, T.G., Degenhardt, J., Hiltpold, I., Toepfer, S., Kuhlmann, U., Gershenzon, J., and Turlings, T.C. (2005). Recruitment of entomopathogenic nematodes by insect-damaged maize roots. Nature 434, 732-737. Abstract Article

Richardson, W.H., Schmidt, T.M., and Nealson, K.H. (1988). Identification of an anthraquinone pigment and a hydroxystilbene antibiotic from Xenorhabdus luminescens. Appl. Environ. Microbiol. 54, 1602-1605. Abstract

Sandhu, S.K., Jagdale, G.B., Hogenhout, S.A., and Grewal, P.S. (2006). Comparative analysis of the expressed genome of the infective juvenile entomopathogenic nematode, Heterorhabditis bacteriophora. Mol. Biochem. Parasitol. 145, 239-244. Abstract Article

Strauch, O., and Ehlers, R.U. (1998). Food signal production of Photorhabdus luminescens inducing the recovery of entomopathogenic nematodes Heterorhabditis spp in liquid culture. Appl. Microbiol. Biotechnol. 50, 369-374. Article

Thomas, G.M., and Poinar, G.O.J. (1979). Xenorhabdus new-genus of entomo pathogenic nematophilic bacteria of the family enterobacteriaceae. Int. J. Syst. Bacteriol. 29, 352-360.

Tissenbaum, H.A., Hawdon, J., Perregaux, M., Hotez, P., Guarente, L., and Ruvkun, G. (2000). A common muscarinic pathway for diapause recovery in the distantly related nematode species Caenorhabditis elegans and Ancylostoma caninum. Proc. Natl. Acad. Sci. U.S.A. 97, 460-465. Abstract Article

Watson, R.J., Joyce, S.A., Spencer, G.V., and Clarke, D.J. (2005). The exbD gene of Photorhabdus temperata is required for full virulence in insects and symbiosis with the nematode Heterorhabditis. Mol. Microbiol. 56, 763-773. Abstract Article

Zhou, X., Kaya, H.K., Heungens, K., and Goodrich-Blair, H. (2002). Response of ants to a deterrent factor(s) produced by the symbiotic bacteria of entomopathogenic nematodes. Appl. Environ. Microbiol. 68, 6202-6209. Abstract Article

All WormBook content, except where otherwise noted, is licensed under a Creative SOMRERIGHIS RESERVED Commons Attribution License. 